\title{
Influence of slaughter weight on carcass value, meat quality and drying ability of ham
}

\author{
C. TEXIER, D. DARIDAN \\ Institut Technique du Porc, M. N. E., \\ 149, rue de Bercy, \\ 75579 Paris Cedex 12
}

Some female bacon pigs can be inseminated before the end of their fattening period, notably crossbred LW $\times$ L females among which 2 out of 3 arrive at puberty at the age of 7 months.

Early insemination of these animals at their Ist or and heat (about 95-100 kg live weight) led to obtention of various types of animals :

prepuberal females slaughtered at $100 \mathrm{~kg}$,

females inseminated at $100 \mathrm{~kg}$, but without subsequent pregnancy and thus slaughtered one month later at about $120 \mathrm{~kg}$,

pregnant sows slaughtered (at about $\mathrm{I}_{4} \mathrm{O} \mathrm{kg}$ ) after weaning of their litter.

Comparison of the results obtained by the first two types of animals slaughtered at roo or $120 \mathrm{~kg}$ live weight was in favour of the heaviest sows : better dressing percentage $\left(8_{3}\right.$ versus 80 p. roo), larger difference between selling price and main expenditures, piglet + feed $(+32$ versus + I I F), better meat quality (6.I versus 5.6 for $\mathrm{pH}$ and 23 versus $27 \mathrm{p}$. Ioo for weight loss of the ham during processing.

These results are not very surprising since the heavy pigs were older than the light ones, but the most surprising and particularly encouraging is that both the pig feeder and the butcher may take advantage of this type of animal :

better economic results for the former,

better meat quality for the latter. 